\title{
Systematics, host plants, and life histories of three new Phyllocnistis species from the central highlands of Costa Rica (Lepidoptera, Gracillariidae, Phyllocnistinae)
}

\author{
Akito Y. Kawahara ${ }^{1, \dagger}$, Kenji Nishida ${ }^{2, \ddagger}$, Donald R. Davis ${ }^{3, \S}$ \\ I Department of Entomology, University of Maryland, 4112 Plant Sciences Building, College Park, MD \\ 20742 USA 2 Escuela de Biología, Universidad de Costa Rica, 2060 San José, Costa Rica 3 Department \\ of Entomology, NHB-105, National Museum of Natural History, Smithsonian Institution, PO Box 37012, \\ Washington, D.C., 20013-7012 USA \\ † urn:lsid:zoobank.org:author:AEE810A3-1680-434B-89C5-F27AF4C97C84 \\ † urn:lsid:zoobank.org:author:E936E053-36E1-4087-AEBE-796C8EB59A2A \\ § urn:lsid:zoobank.org:author:FC851800-FEE2-46CF-8C55-B4A2D5EEFF66 \\ Corresponding author: Akito Y. Kawahara (kawahara@umd.edu) \\ Academic editor:J. Donald Lafontaine | Received 17 August 2009| Accepted 21 November 2009 | Published 9 November 2009 \\ urn:lsid:zoobank.org:pub:C6AA8595-6A57-4ACD-B0A1-3AE36F7C8701 \\ Citation: Kawahara AY, Nishida K, Davis DR (2009) Systematics, host plants, and life histories of three new Phyllocnistis \\ species from the central highlands of Costa Rica (Lepidoptera, Gracillariidae, Phyllocnistinae). ZooKeys 27: 7-30. doi: \\ 10.3897 /zookeys.27.250
}

\begin{abstract}
Three new species of Phyllocnistis Zeller are described from the central highlands of Costa Rica: Phyllocnistis drimiphaga sp. n., P. maxberryi sp. n., and P. tropaeolicola sp. n. Larvae of all three are serpentine leaf miners. Phyllocnistis drimiphaga feeds on Drimys granadensis (Winteraceae), P. maxberryi on Gaiadendron punctatum (Loranthaceae), and P. tropaeolicola on Tropaeolum emarginatum (Tropaeolaceae). All specimens were collected as larvae or pupae in their mines and reared in captivity. Parasitoid wasps were reared from $P$. drimiphaga and $P$. maxberryi. Description of the adults, pupae, and life histories are supplemented with photographs, illustrations, and scanning electron micrographs.
\end{abstract}

\section{Keywords}

Drimys, Encyrtidae, Eulophidae, Gaiadendron, Neotropical, Phyllocnistis, pupal morphology, serpentine leaf miner, taxonomy, Tropaeolum

Copyright A.Y. Kawahara et al. This is an open access article distributed under the terms of the Creative Commons Attribution License, which permits unrestricted use, distribution, and reproduction in any medium, provided the original author and source are credited. 


\section{Introduction}

Phyllocnistis Zeller includes 87 described species, many of which are very small, with silvery vestiture, and similar in appearance (De Prins and De Prins 2005, 2009). The genus has been generally poorly studied because of its small size and difficulty to identify species. The precise taxonomic placement of the genus has also remained questionable because of a lack of shared adult morphological characters with other microlepidoptera (De Prins and Kawahara, 2009).

Only two species of Phyllocnistis were known to occur in Costa Rica (De Prins and De Prins 2005, 2009), one of which is citrus leaf miner, P. citrella Stainton, 1856, and the other, the mahogany leaf miner, P. meliacella Becker, 1974. Phyllocnistis citrella, originally from the Old World, was first reported in the Americas in 1993 (Heppner 1993) and has since become established in nearly every major citrus growing region in the New World. The larva of citrella is restricted to the plant family Rutaceae, and the larva of meliacella is known to feed only on members of the Meliaceae.

The larva of Phyllocnistis is unusual in having three or more sap-feeding instars and one non-feeding, highly specialized cocoon-spinning instar (Davis 1987). The larva creates a long, slender, subepidermal serpentine mine with a characteristic median frass line at the terminus of which a pupal chamber (pupal cocoon fold) is constructed, usually from the curled edge of the leaf (Davis 1994). On the basis of its unique mine, a phyllocnistine fossil has been identified as the oldest fossil in the Ditrysia, dated from leaf impressions from the Cretaceous (Grimaldi and Engel 2005; Labandeira et al. 1994), the bedrock which was recently reevaluated to be -102 million years Ma (Brenner et al. 2000).

In general, larval morphological characters poorly define species of Phyllocnistis. From our experience rearing North American Phyllocnistis with David Wagner and others, pupal morphology provides the most informative characters for distinguishing species in the genus. In particular, we have found the shape of the frontal ridge (cocoon-cutter) and hooks on the dorsal surface of the abdominal segments to be very useful. These structures are respectively used to cut the cocoon and anchor it during adult emergence. We describe the adults, pupae, and life histories of the three new species of Phyllocnistis found in the central highlands of Costa Rica.

\section{Methods}

Study sites and habitats. Field studies were conducted at four high elevation sites between 1950-3100 m in the central region of Costa Rica during July 2001, AprilMay and November 2002, February-April 2003, December 2003-January 2004, March-April 2004, May 2005, September 2008, and July 2009. Three sites were located on Cerro de la Muerte, in the northern to central region of Cordillera de Talamanca (Fig. 1A). This region is cold and humid with 1-2 months of dry season (Herrera and Gómez 1993). According to Kappelle (1996), annual rainfall ranges 

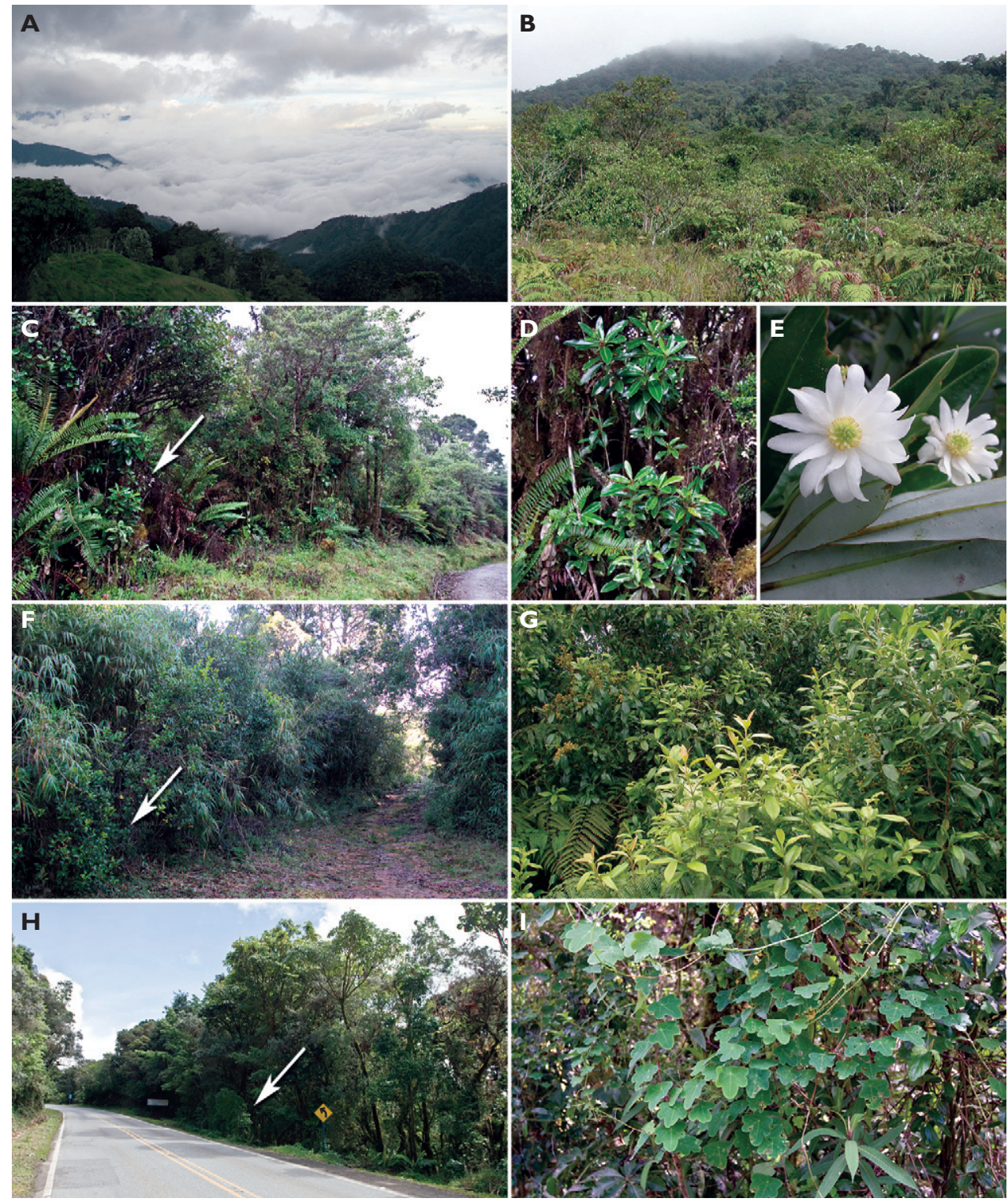

Figure I. Habitats and larval host plants of Phyllocnistis species. A Cerro de la Muerte, Villa Mills region, $3000 \mathrm{~m}$ and below, in Cordillera de Talamanca B Volcán Barva, ALAS transect, $2000 \mathrm{~m}$, in Braulio Carillo National Park $\mathbf{C}$ habitat of $P$. drimiphaga in Cerro de la Muerte, km 70 Pan-American Hwy, road to El Paraíso del Quetzal, $2700 \mathrm{~m}$, arrow pointing to host plant where mines were found $\mathbf{D}$ young stem shoots and leaves of Drimys granadensis of $\mathrm{C}$, growing from base of the tree $\mathbf{E}$ flowers and leaves of $D$. granadensis $\mathbf{F}$ habitat of $P$. maxberryi in Cerro de la Muerte, km 95 Pan-American Hwy, trail front of La Georgina in Villa Mills, 3100 m, arrow pointing to host plant where mines were found $\mathbf{G}$ young growth of Gaiadendron punctatum in front, and mature trees with yellow fruits in behind, at ALAS transect in Vara Blanca, $2000 \mathrm{~m} \mathbf{H}$ habitat of $P$. tropaeolicola in Cerro de la Muerte, on km 95 Pan-American Hwy, near La Gegina in Mills, 3100 m, arrow pointing to host plant where mines were found I Tropaeolum emarginatum, details of host plants that are shown in $\mathrm{H}$. 
from 2000 to $3500 \mathrm{~mm}$ and average daily temperature is $11^{\circ} \mathrm{C}$, with temperatures at night occasionally falling below $0{ }^{\circ} \mathrm{C}$ during the dry season. Sleet and heavy frost has been observed at Mills region (Oscar Abarca, pers. comm.). One of the sites on Cerro de la Muerte was near Villa Mills, at the $95 \mathrm{~km}$ mark of the Pan-American Highway $\left(09^{\circ} 33^{\prime} 30.0^{\prime \prime} \mathrm{N}, 083^{\circ} 43^{\prime} 25.8^{\prime \prime W}, 3100\right.$ m; Fig. 1, H). Another site was near the road leading to El Paraíso del Quetzal at the $70 \mathrm{~km}$ mark of the Pan-American Highway (2774 m, 09³3'45.6"N, 08350'50.1"W; Fig. 1C). This road divides Parque Nacional Tapantí-Macizo de la Muerte and Parque Nacional Los Quetzales/Reserva Forestal Los Santos of San José Province. The third site on Cerro de la Muerte was on the road to the Genesis II Cloud Forest Preserve, $4 \mathrm{~km}$ NE of La Cañón in Cartago Province $\left(09^{\circ} 42^{\prime} 23.4^{\prime \prime} \mathrm{N}, 083^{\circ} 54^{\prime} 35.9^{\prime \prime} \mathrm{W}, 2385 \mathrm{~m}\right)$.

The fourth site was in Cordillera Volcánica Central, $6 \mathrm{~km}$ ENE of Vara Blanca, part of Volcán Barva in Parque Nacional Braulio Carrillo (10 $10^{\prime} 51$ "N, $084^{\circ} 06^{\prime} 20^{\prime \prime W}$, 1950-2050 m; Fig. 1B). This collecting site was near the edge of a swampy open field and oak forest. The weather of this locality is consistently cool and humid throughout the year (Herrera and Gómez 1993). Typical weather at this site is rainy and windy, with a few hours of daily sunshine and temperatures ranging from $5-11{ }^{\circ} \mathrm{C}$ (Nishida 2006).

Leaf mine sampling and rearing. Leaf mines were collected and placed in transparent plastic bags or vials and larvae were reared at Universidad de Costa Rica, San José $\left(1200 \mathrm{~m}\right.$ elevation). Each day, mines were placed in a refrigerator $\left(7.0-8.0^{\circ} \mathrm{C}\right)$ and transferred to ambient temperature $\left(-20^{\circ} \mathrm{C}\right)$ to simulate natural conditions at high elevations. Reared parasitoids and samples of the mature larva and pupa of each species were preserved in 75-80 \% EtOH. Adult moths were pinned, spread, and doublemounted. All adult specimens in this study were obtained from reared immatures.

Photography and dissection. Photographs of leaf mines were taken primarily in the field using Nikon Coolpix 4500, 8700, and Canon G7 digital cameras. Some pupae were dried and sputter-coated with a 60:40 mixture of gold-palladium for examination with a scanning electron microscope (SEM). SEM photographs were taken using an Amray 1810 SEM with a lanthanum hexaboride (LaB6) source at an accelerating voltage of $10 \mathrm{kV}$. Illustrations of the genitalia were sketched with a camera lucida attached to a stereomicroscope.

Type deposition, nomenclature, and diagnosis. Type specimens are deposited in the United States National Museum of Natural History, Smithsonian Institution (USNM), Museo de Zoología, Escuela de Biología, Universidad de Costa Rica (UCR), and Instituto Nacional de Biodiversidad, Santo Domingo de Heredia, Costa Rica (INBio). Scientific names of plants follow Missouri Botanical Garden (2009). Adult wing pattern nomenclature is explained in Fig. 3; diagnostic features of the three species are summarized in Table 1. 


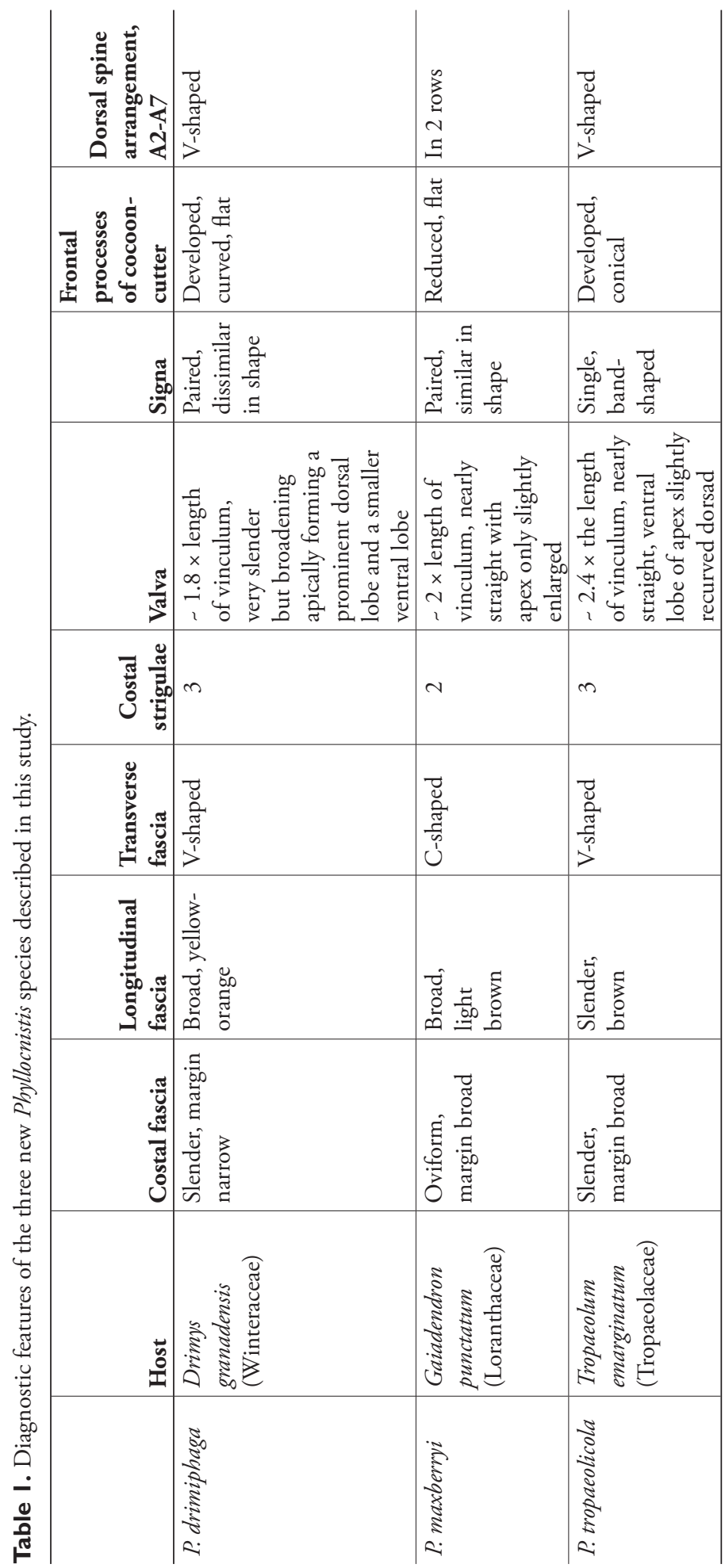




\section{Adult, pupa, and life history descriptions}

\section{Phyllocnistis drimiphaga Kawahara, Nishida \& Davis, sp. n.} urn:lsid:zoobank.org:act:48662DAE-2362-4959-A0B2-C9339B31BB1F

Diagnosis (Table 1). Phyllocnistis drimiphaga is similar to P. maxberryi, but is larger and has slender, sharply angled costal fascia, V-shaped transverse fascia, three costal strigulae, and dissimilar signa. Phyllocnistis drimiphaga differs from $P$. tropaeolicola in having broad longitudinal fascia, genital valva that are only $\sim 1.8 \times$ the length of the vinculum, and paired signa. The pupa has curved, flattened frontal processes, which are reduced in $P$. maxberryi and conical in $P$. tropaeolicola.

Adult (Fig. 2A). Forewing length 2.9-3.5 mm. Head. Vestiture consisting of smooth, broad, silvery-white scales that overlap anterior margin of eye. Antenna equal to length of forewing, scape and pedicel enlarged laterally and covered with lanceolate scales, a single row of fine short scales completely encircling each flagellomere. Labial palpus long, slender, $-1.0 \mathrm{~mm}$ in length, covered with lustrous white scales. Thorax. Forewing silvery white; with a long pale yellowish-orange longitudinal fascia with dark-gray margins extending 2/3 length of forewing slightly diagonal from base of costa to strongly oblique, costal fascia of similar color across distal third of wing; apex of forewing with three slender, fuscous, costal strigulae; apical to subapical pale yellowish orange bordered by gray; three apical, fuscous strigulae arising from small black apical spot, and one tornal, fuscous strigula also from apical spot; ventral surface mostly dark brown. Hindwing creamy white. Legs mostly silvery white; foretibia fuscous dorsally; fore- and mid-tarsomeres lightly suffused with cream scales dorsally. Abdomen. Length $-2.0 \mathrm{~mm}$, covered in long silver scales. Coremata present on segment VIII of male, consisting of a pair of elongate, inflatable tubular extensions bearing a terminal cluster of long slender scales (Fig. 4A). Male genitalia (Figs 4A-C). Uncus absent; tegumen complex, consisting of a narrow, sclerotized dorsal arch, continuing caudally, often slightly beyond apex of valva, as an elongate, mostly membranous, basally spinose cylinder that encloses the anal tube; vinculum well developed, $-0.6 \times$ length of valva, U- to $\mathrm{V}$-shaped with relative narrow anterior end; valva (Fig. 4B) relatively long, $-1.8 \times$ length of vinculum, generally slender with a moderately broad base, very slender for most of its length, then broadening apically to form a prominent dorsal lobe and a smaller ventral lobe (Fig. 4A); transtilla arising from mesal base of valva as an elongate, acute process, and continuing mesally to articulate at midline with process from opposite valva. Aedeagus (Fig. 4C) slender, weakly sclerotized, externally finely wrinkled cylinder, - equal to length of valva; cornuti absent; phallobase greatly extended as a membranous tube $-1.7-2.0 \times$ length of aedeagus; terminal hood of phallobase abruptly inflated and curved at right angle to phallobase. Genitalia slide USNM 33208. Female genitalia (Figs 4D, E). Oviscapt greatly reduced; posterior apophyses very short, $\sim 0.8 \times$ length of papillae anales; anterior apophyses slightly longer, $-1.3 \times$ length of posterior apophyses; ostium bursae opening in 


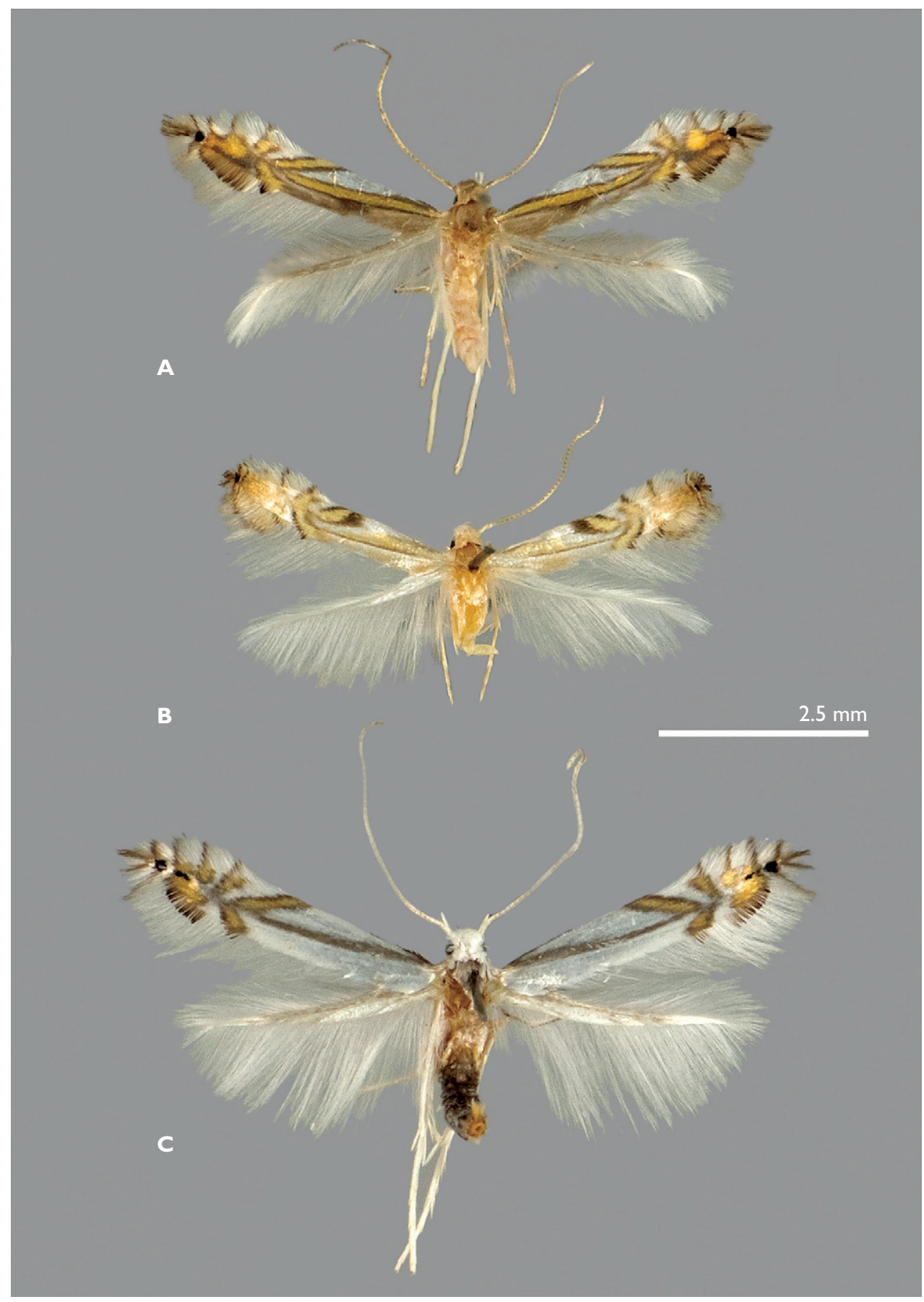

Figure 2. Adults of three new Phyllocnistis species from Costa Rica. A Phyllocnistis drimiphaga sp. n., holotype female B P. maxberryi sp. n., holotype female (abdomen removed for dissection) C P. tropaeolicola sp. n., holotype male. 


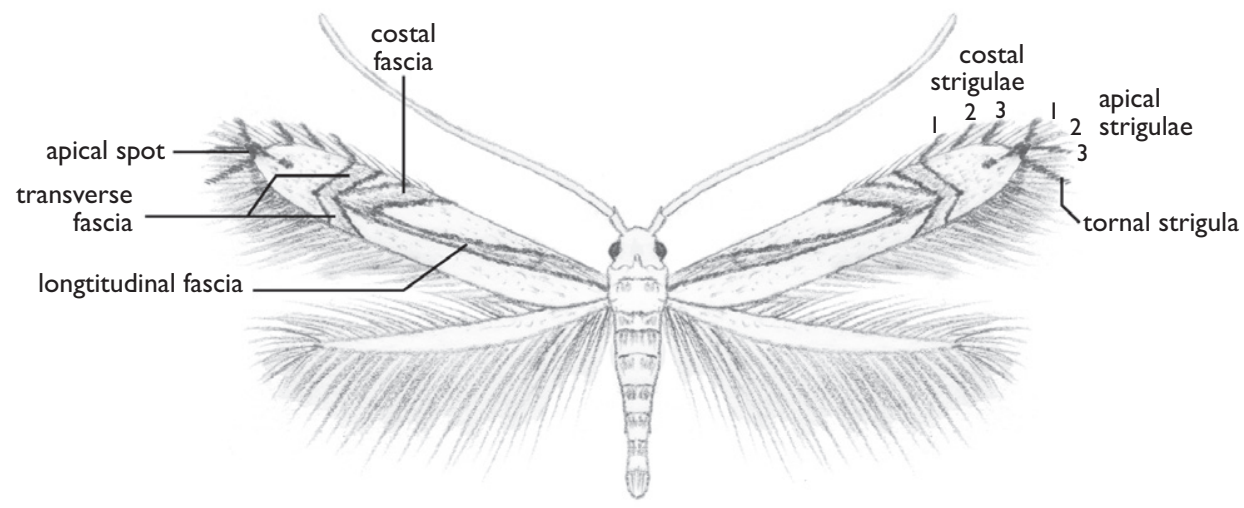

Figure 3. Nomenclature of Phyllocnistis forewing fasciae and strigulae.

membrane between sterna 7 and 8; ductus bursae completely membranous, slender, elongate, over $7.5 \times$ length of papillae anales and terminating near caudal fifth of corpus bursae; corpus bursae greatly enlarged, $-0.7 \times$ length of ductus bursae; walls of corpus bursae membranous except for a pair of ligulate and very dissimilar signa; longest signum $-3 \times$ length of shorter member and with 5 short, acute to rounded, flattened spines projecting from one side of signum; shorter signum with a single, blunt, flattened, rounded spine projecting from middle; length of spines equal to width of signa; ductus seminalis extremely slender, elongate, $\sim 2.3 \times$ length of corpus bursae and arising from anterior end of corpus bursae. Genitalia slides USNM 33207, 33273.

Larva (Figs 10F, G). Mature sap-feeding larva $-6.5 \mathrm{~mm}$ long, yellowish white, head capsule translucent pale brown (Fig. 10F). Last instar (cocoon-spinning) larva yellowish white, head capsule yellowish white; $-6.2 \mathrm{~mm}$ long (Fig. 10G).

Pupa (Figs 7, 10I). Dark brown, up to $-3.8 \mathrm{~mm}$ long, diameter $-0.75 \mathrm{~mm}$. Vertex with a stout, triangular frontal process (cocoon-cutter) transversed by a pair of shorter, curved spines (Figs 7A-E), and single pair of long setae at base of frons (Fig. 7C). Dorsum of A2-A7 with a pair of curved, large spines, arranged roughly in the shape of a V, in between which is a concentration of smaller spines projecting posteriorly (Figs 7F-H); each segment with a pair of long, lateral, sensory setae (Fig. 7K). A10 prominently furcated (Figs 7I, J, L), with a pair of slightly divergent acute processes from caudal apex. Pupal slide USNM 34034.

Types. Holotype (Fig. 2A): ㅇ, COSTA RICA: Prov. Heredia, 6 km ENE Vara Blanca, $2050 \mathrm{~m}, 10^{\circ} 10^{\prime} 34^{\prime \prime} \mathrm{N}, 084^{\circ} 06^{\prime} 41^{\prime \prime} \mathrm{W}, 27$ Jan 2004, adult emergence, INBio-OET-ALAS transect, col./rear Kenji Nishida, pupa collected 30 Dec 2003, host plant Drimys granadensis. Leaf miner on underside (USNM). Paratypes: Immatures: Prov. Cartago: Cerro de la Muerte, La Cañón, Genesis II Cloud Forest Preserve, $2422 \mathrm{~m}, 09^{\circ} 42^{\prime} 23.4^{\prime \prime N}, 8^{\circ} 54^{\prime} 36.1^{\prime \prime W}: 2$ sap-feeding larvae, 1 pupa, 12 Sep 2008, Kenji Nishida, host Drimys granadensis; Prov. San José: Cerro de la Muerte, 


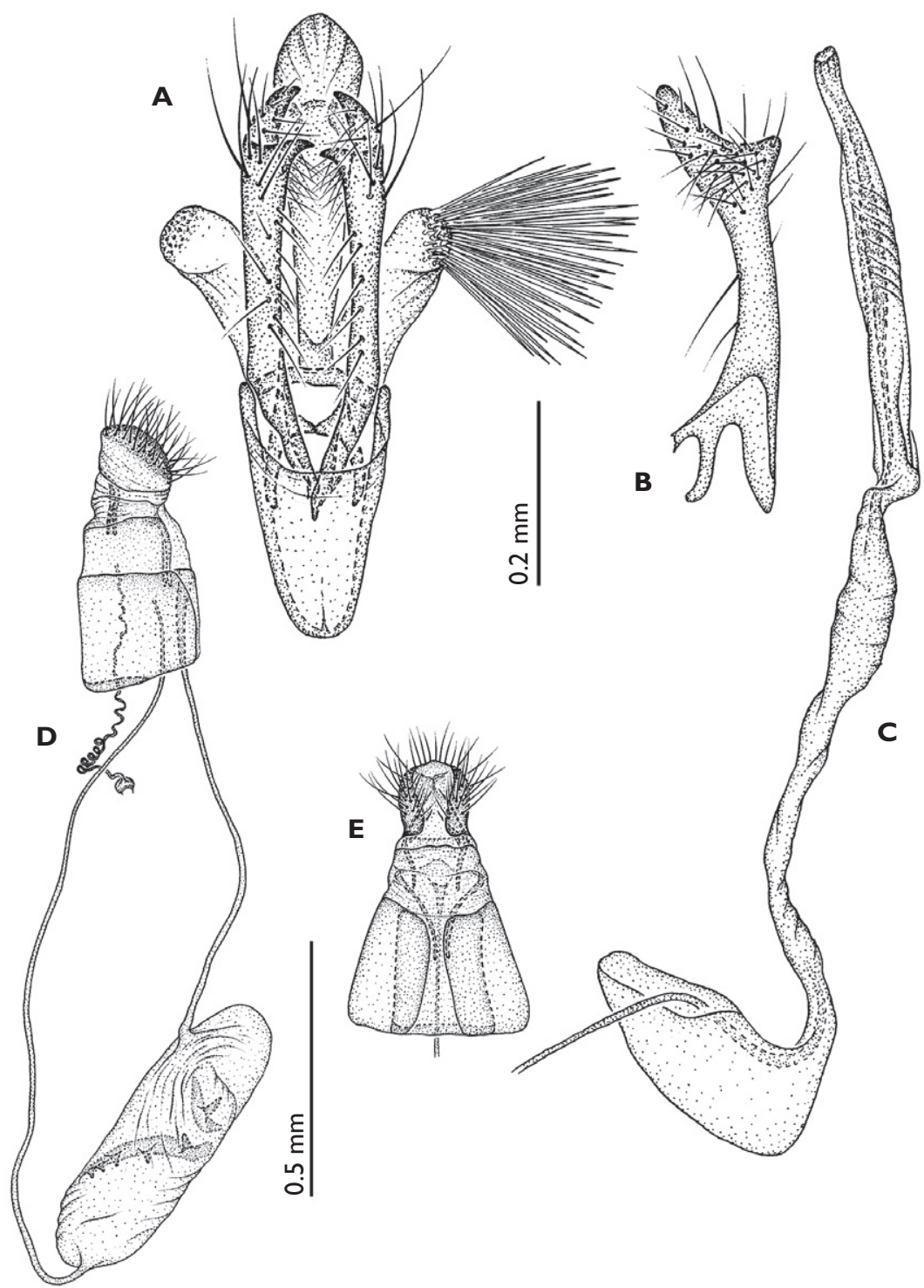

Figure 4. Phyllocnistis drimiphaga sp. n., genitalia. A Male, ventral view B right valva, mesal view C aedeagus $\mathbf{D}$ female, lateral view $\mathbf{E}$ ventral view of terminal segments. (Scale bar $0.5 \mathrm{~mm}$ except for figure B, $0.2 \mathrm{~mm}$.)

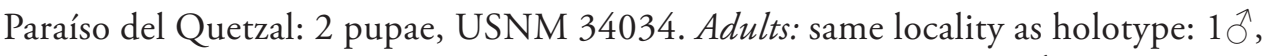
26 Jan 2004, USNM 33208; 1 , 26 Jan 2004, USNM 33207; $10^{\Uparrow}, 1$ 우 (USNM 33273), 28 Jan 2004. 1 ㅇ adult paratype at INBio and UCR, the remaining paratypes at USNM.

Life history (Fig. 10). Mines are narrow, long, and serpentine, with a brown median frass line (Figs 10A, C, D) covering most areas of the leaf on small leaves $(<6$ 
$\mathrm{cm}$ ) or half the area in larger leaves. Mines were found on relatively young leaves near the apex of branches, from branches close to the ground up to $-3 \mathrm{~m}$ on young trees, along shaded areas of forest trails (Fig. 1C) or in the understory. We observed 43 of 48 mines on the abaxial side of the leaf (Fig. 10A), and the remaining mines on the adaxial side (Fig. 10D). Most mines were singly found on a leaf; however seven of 38 mined leaves carried two mines, either two on the abaxial side or one on both sides. All but one adaxial mine began near the mid-vein and extended along it (Fig. 10D). Mature mines are yellowish green in color (Fig. 10C). Mining on small, soft, youngleaves frequently caused the leaf margin to curl. We were unable to study the upper canopy for leaf mines.

Early stage mines were typically in the shape of a whorl (Figs 10A-C). Flat, oval egg shells were found attached to the leaf surface in the middle of an early mine whorl (Fig. 10B). A pupal cocoon fold ( $-6.5 \mathrm{~mm}$ long), typical of Phyllocnistis, was found along leaf margins (Figs 10A, H, J) both on the adaxial (Fig. 10H) and abaxial sides (Figs 10A, J).

In 70 examined mines, only 20 had a live larva or pupa. Remaining mines either were empty or contained dead, early to middle stage sap-feeding larvae. Mortality of sap-feeding stages was most likely caused by desiccation after rupturing of the epidermal layer and by a cf. Ceraphron (Ceraphronidae) parasitoid wasp. In some pupal folds, a pupal shell of an entedonine wasp (Eulophidae) was found with a shrunken $P$. drimiphaga pupal shell. In others, cocoons of Ageniaspis sp. (Encyrtidae) were found in a last instar (cocoon-spinning) larval pelt (Fig. 10K).

We also discovered active mines of Marmara sp. (Gracillariidae) on the abaxial side of same host along the road to El Paraíso del Quetzal. Compared to those of P. drimiphaga, mines were much narrower, whiter, less serpentine, and were typically found near leaf margins.

Host. Drimys granadensis L. f. (Winteraceae) (Fig. 1D). Drimys Foster \& Forster is the only genus in the family Winteraceae found in the New World tropics (Doust and Drinnan 2004). All other genera of Winteraceae are found in the Old World southern hemisphere with a center of diversity in Southeast Asia (Gentry 1996; Hartshorn 1983). Drimys granadensis, commonly known as 'chilemuelo' or 'quiebra muelas', has been recorded from central Mexico $\left(-20^{\circ} \mathrm{N}\right)$ south through Central America to northern Peru $\left(-5^{\circ} \mathrm{S}\right)$ (Missouri Botanical Garden 2009). Trees grow to nearly $15 \mathrm{~m}$ in height and are characterized by pepper-flavored leaves with white underside surfaces and aromatic bright, white flowers (Fig. 1E), found mostly in primary forest (AlfaroVindas 2003). In Costa Rica, the species has been recorded between 1100 and $3700 \mathrm{~m}$ elevations on both Pacific and Atlantic slopes. Large young leaves are pale green color, sized $~ 10-15 \mathrm{~cm}$ long and 2-4 cm wide (KN, pers. obs.).

Distribution. Known only from cloud forests above $2000 \mathrm{~m}$ in Cordillera de Talamanca and Cordillera Volcánica Central. More specifically, specimens have been collected from Heredia Province, $6 \mathrm{~km}$ ENE of Vara Blanca; San José Province, Cerro de la Muerte, Paraíso del Quetzal; and Cartago Province, Cerro de la Muerte, Genesis II Cloud Forest Preserve. In February 2009, several additional old leaf mines 
were observed in Chirripó National Park along the main trail between 2200 and $2700 \mathrm{~m}$ elevation.

Etymology. The species name, drimiphaga, comes the host plant genus, Drimys, and the Greek word phaga, meaning "to eat".

\section{Phyllocnistis maxberryi Kawahara, Nishida \& Davis, sp. n.} urn:lsid:zoobank.org:act:598E20A2-D76F-41A2-83A0-CA268EC0DF41

Diagnosis (Table 1). Phyllocnistis maxberryi differs from $P$. drimiphaga and P. tropaeolicola in having an oviform costal fascia with a broad margin, a C-shaped transverse fascia, two costal strigulae, and paired signa that are similar in shape. Unlike drimiphaga and tropaeolicola, the pupa of maxberryi has less developed frontal processes and two parallel rows of spines on the dorsal surface of abdominal segments. Of the three new Phyllocnistis species proposed in this paper, P. maxberryi is morphologically most similar to P. meliacella Becker. Phyllocnistis maxberryi may be distinguished from the latter by its broader apex of the valva and proportionately larger signa.

Adult (Fig. 2B). Forewing length 2.2-3.7 mm. Head. Vestiture silvery white, completely covered with smooth, broad, scales that overlap anterior margin of eye; occipital scales cream. Antenna - equal or slightly longer than length of forewing, scape and pedicel enlarged laterally and covered in long silvery scales, a single row of slender mostly silvery-white scales completely encircling each flagellomere; dorsal surface of antenna with a pale-golden luster. Labial palpus slender, $\sim 0.5 \mathrm{~mm}$ in length, with silvery-white scales. Thorax. Forewing silvery white, with a single, broad, light-brown longitudinal fascia with a dark brown posterior margin extending slightly diagonal from base of costa joining costal fascia at midway to apex; costal fascia oblique, pale gold, oviform, with a broad, inner dark-brown margin; transverse fascia C-shaped, pale gold with dark margin; apical to subapical area pale yellow; two faint, dark-brown costal strigulae present; a single, small black spot at wing apex from which two dark-brown apical strigulae arise. Hindwing silvery white. Legs mostly silvery white, with a faint suffusion of pale gold dorsally over most segments. Abdomen. Length $\sim 1.5-2.0 \mathrm{~mm}$, silvery white; coremata similar to $P$. drimiphaga. Male genitalia (Figs 5A-C). Similar to $P$. drimiphaga except vinculum relatively broader and more $U$-shaped. Valva $\sim 2 \times$ length of vinculum, nearly straight with apex only slightly enlarged (Fig. 5A). Genitalia slide USNM 33279. Female genitalia (Figs 5D-F). Oviscapt greatly reduced as in $P$. drimiphaga; ductus bursae completely membranous, slender, elongate, over $12 \times$ length of papillae anales and terminating near middle of corpus bursae; corpus bursae greatly enlarged, $-0.7 \times$ length of ductus bursae; signa paired, closely similar in shape and size (fusiform), with more posterior signum $~ 1.2-1.5 \times$ longer than anterior signum; each signum with a single, acute, flattened spine projecting from middle (Fig. 5F); length of spines slightly more than width of signa; ductus seminalis extremely slender, elongate, - 1.9 $\times$ length of corpus bursae and arising from anterior end of corpus bursae. Genitalia slides USNM 33280, 33286. 


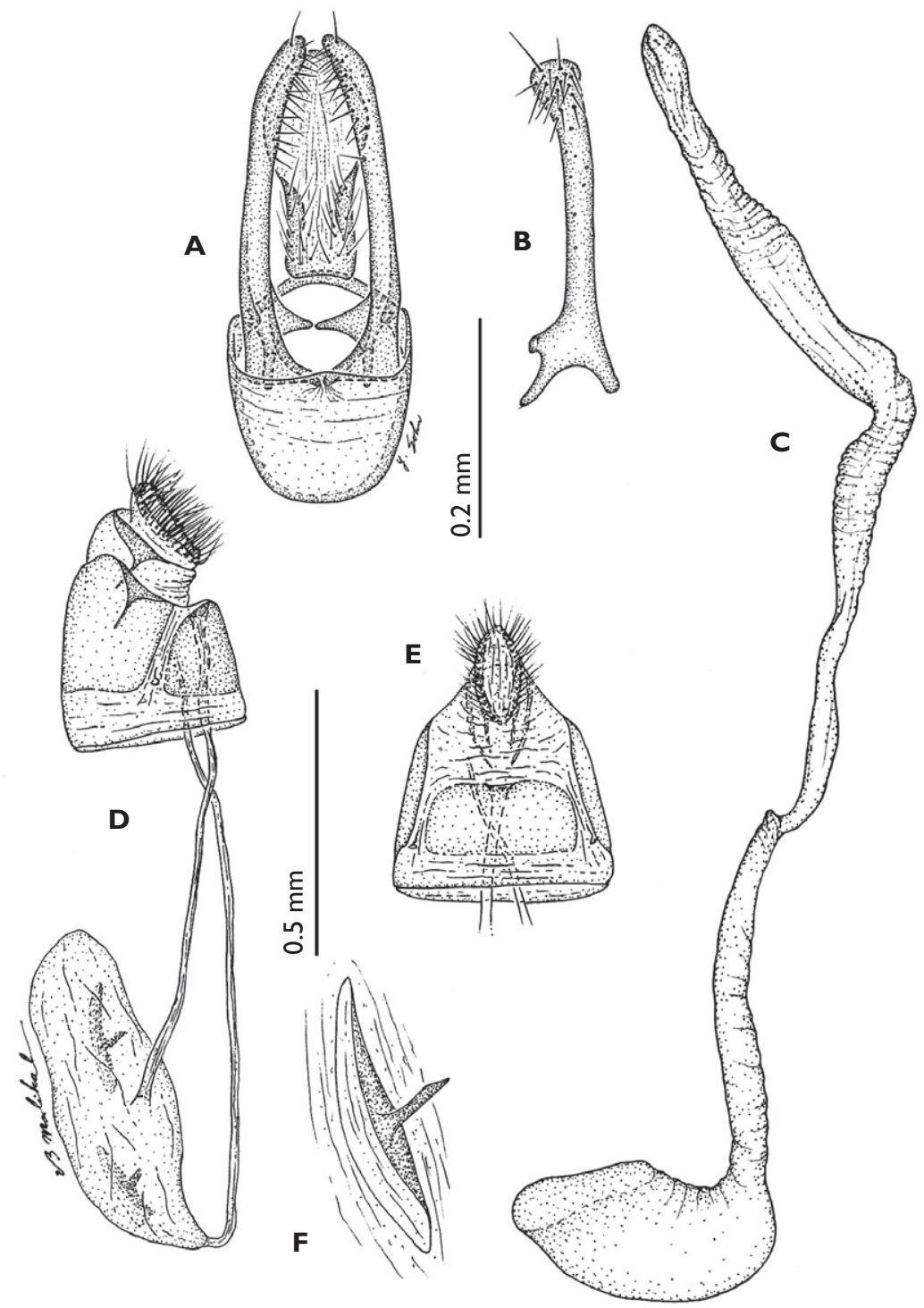

Figure 5. Phyllocnistis maxberryi sp. n., genitalia. A Male, ventral view B right valva, mesal view C aedeagus $\mathbf{D}$ female, lateral view $\mathbf{E}$ ventral view of terminal segments $\mathbf{F}$ signa. (Scale bar $0.5 \mathrm{~mm}$ except for figure $\mathrm{B}, 0.2 \mathrm{~mm}$.)

Larva (Figs 11C-F). Mature sap-feeding larva $-6.0 \mathrm{~mm}$ long, translucent orange, head capsule brown, prothoracic shield brown (Figs 10C-E). Last instar (cocoon-spinning) larva orange, head capsule orange, $-6.3 \mathrm{~mm}$ long (Fig. 10F).

Pupa (Figs 8; 11H, I). Brown, length up to $-4.0 \mathrm{~mm}$; diameter $-0.85 \mathrm{~mm}$. Vertex with a long, dorsally curved, spine-like process (cocoon-cutter) (Figs 8A, B, D, E), and two pairs of short setae (Fig. 8C). Dorsum of A2-A7 with a pair of laterally curved, large spines in between which is a concentration of smaller spines, projecting 
posteriorly that are roughly arranged in two parallel rows (Figs $8 \mathrm{~F}-\mathrm{H}$ ); each segment with a pair of long, lateral, sensory setae (Fig. 8K). A10 with a pair of slightly divergent processes from caudal apex (Figs 8I, J, L).

Types. Holotype (Fig. 2B): $ᄋ$, Costa Rica: Prov. San José, Cerro de la Muerte, Villa Mills, 3100 m, 13 Mar 2003 (adult emergence), host Gaiadendron punctatum, upper leaf miner, col./rear Kenji Nishida, DRD 4474 (USNM). Paratypes: Immatures: same locality as holotype: 3 pupae (USNM 33732), 5 Mar 2003, K. Nishida; 3 larvae, 2 pupae, 2 Apr 2003, K. Nishida; 1 larva, 21 May 2002, K. Nishida; 3 larvae, 1 pupa (USNM 34024), 10 Mar 2004, K. Nishida. One pupa, Villa Mills, trail front of La Georgina, 3103 m, 12 Sep 2008, K. Nishida, host Gaiadendron punctatum. Two larvae, 1 pupa, Prov. Heredia, $6 \mathrm{~km}$ ENE Vara Blanca, 10 $11^{\circ} \mathrm{N}$, $84^{\circ} 07^{\prime} \mathrm{W}, 2050$ m, 10 May 2005, K. Nishida; 1 pupa, 23 Nov 2002, K. Nishida. Adults: same locality as holotype: $1 \hat{\jmath}, 22$ Mar 2003, K. Nishida; 20, 26 Mar 2003, K. Nishida; $0^{\lambda}, 2$, Prov. Heredia, $6 \mathrm{~km}$ ENE Vara Blanca, $10^{\circ} 11^{\prime} \mathrm{N}, 84^{\circ} 07^{\prime} \mathrm{W}$, 1950-2050 m, 2 Feb 2003, K. Nishida; 20̂, 9 Apr 2002, 1900 m, emerged 22-28 Apr 2002, host Gaiadendron punctatum, D. and M. Davis. $\widehat{O}$ slide USNM 33279; o slides USNM 33280, 33286. One paratype, unknown sex (missing abdomen) at UCR, remaining paratypes at USNM.

Life history (Fig. 11). Active mines were found on fully open young leaves near the tip of a branch. The smallest leaf with an active mining larva measured $12 \times 30$ $\mathrm{mm}$. Mines were generally found on young plants about $30 \mathrm{~cm}$ to $1.5 \mathrm{~m}$ tall, in open fields or along exposed dirt roads or trails. In an open swampy field at the ALAS transect near Vara Blanca, many active mines were found on new leaves on young plants less than $1.5 \mathrm{~m}$ tall (Fig. 11A) and very few active mines were found on larger plants bearing flowers or fruit.

Thirty-six of 42 leaves had mines on the adaxial side and the rest had mines on the abaxial side or on both. Up to three mines were observed on a single leaf. These mines were relatively short, serpentine mines with a brown median frass line that became dark brown as the mine widened (Fig. 11C).

We recognize a general mining pattern for $P$. maxberryi: the egg is laid on the mid-vein, near the center of the leaf (Fig. 11C). After hatching, the larva enters the leaf and mines proximally towards the leaf petiole along the mid-vein and turns toward the leaf apex near or at the leaf petiole and mines along the leaf margin. Before reaching the midpoint along the axis of the leaf, the larva travels inward between the mid-vein and leaf margin and travels towards the leaf apex. After nearing the apex, the larva crosses the mid-vein and begins mining the other half of the leaf in a relatively straight line turning back towards the petiole. Once near the petiole, the larva constructs an oval-shaped chamber and molts within. After molting, the cocoon-spinning instar folds the margin while spinning its cocoon. This pupal fold was typically $-7.0 \mathrm{~mm}$ long (Figs $11 \mathrm{~B}, \mathrm{G}$ ). Under rearing conditions, the pupal stage lasts between 21-28 days $(\mathrm{n}=7)$. Five female specimens of Chrysocharis sp. (Eulophidae: Entedoninae) were reared from pupal cocoon folds collected at Villa Mills, Cerro de la Muerte. 
Host. Gaiadendron punctatum (Ruiz \& Pav.) G. Don (Loranthaceae) (Fig. 1G). The free-standing root parasite/epiphyte tree genus Gaiadendron includes approximately 15 species occurring in the New World (Gentry 1996; Missouri Botanical Garden 2009). Gaiadendron punctatum is distributed from Nicaragua through southern Central America to Bolivia $\left(-17^{\circ} 50^{\prime} \mathrm{S}\right)$ between 600 and $4100 \mathrm{~m}$ elevation (INBio 2009; Missouri Botanical Garden 2009). Trees are typically $2-5 \mathrm{~m}$ in height with bright yellow/orange flowers (Kappelle 2008). Young leaves are pale green to reddish brown, about 3-6 cm long and $1-3 \mathrm{~cm}$ wide (KN, pers. obs.). Among species in the genus, only $G$. punctatum is known from Costa Rica, and it has been recorded above $1500 \mathrm{~m}$ in open areas and along trails in cloud forests (INBio 2009; Kappelle 2008).

Distribution. This species appears to have a greater elevational range than the other two, being found between 1950 and $3100 \mathrm{~m}$. Specimens have been collected from Heredia Province, $6 \mathrm{~km}$ ENE of Vara Blanca, in the Cordillera Volcánica Central; and Cartago Province, Cerro de la Muerte, Villa Mills, in Cordillera de Talamanca.

Etymology. Named for the Honorable Max N. Berry of Washington, D.C., an honorary member of the Smithsonian National Board.

\section{Phyllocnistis tropaeolicola Kawahara, Nishida \& Davis, sp. n.}

urn:lsid:zoobank.org:act:E766981C-D9EC-48DF-9C9D-D02EC2AC9744

Diagnosis (Table 1). Phyllocnistis tropaeolicola differs from P. drimiphaga and P. maxber$r y i$ in its larger size, having a slender longitudinal fascia, valva that are $-2.4 \times$ the length of the vinculum, and a single, band-shaped signa. The pupa of $P$. tropaeolicola has conical frontal processes and dorsal abdominal spines on each segment are arranged in a V.

Adult (Fig. 2C). Forewing length $2.6-5.0 \mathrm{~mm}$. Head. Vestiture silvery white, completely covered with smooth, broad, scales slightly overlapping anterior margin of eyes. Antenna - equal to length of forewing, scape and pedicel enlarged laterally and covered in long silvery scales, a single row of fine short scales completely encircling each flagellomere. Labial palpus long, slender, $-1.0 \mathrm{~mm}$. Thorax. Forewing silvery white; with a slender, dark-brown, longitudinal fascia extending $2 / 3$ length of wing to meet distally at junction of brown, costal and transverse fasciae; costal fascia slender and strongly oblique with dark-brown border; transverse fascia V-shaped, with a dark-brown border; apical to subapical area pale yellowish orange with a small black spot; three slender, dark-brown costal strigulae, three slender dark-brown apical strigulae, and one faint brown tornal strigula arising from black apical spot; fringe along tornal margin white with a dark-brown basal band of broad scales. Hindwing mostly white except for a band of pale brown scales extending length of costal margin. Legs similar to $P$. drimiphaga, silvery white except dark brown over dorsal surface of femur, tibia and tarsus of foreleg. Abdomen. Length $-2.0 \mathrm{~mm}$, mostly brownish gray dorsally, silvery white ventrally. Coremata similar to $P$. drimiphaga. Male genitalia (Figs 6A-C). Similar to $P$. drimiphaga except valva relatively longer and more slender, $-2.4 \times$ the length of vinculum, nearly straight, with ventral 
lobe of apex slightly re-curved dorsad (Fig. 6A). Genitalia slide USNM 33281. Female genitalia (Figs 6D, E). Oviscapt greatly reduced as in $P$. drimiphaga; ductus bursae completely membranous, slender, elongate, $-8.5 \times$ length of papillae anales and terminating at posterior end of corpus bursae; corpus bursae $-0.6 \times$ length of ductus bursae; a single elongate signum present as a narrow band partially encircling middle of corpus bursae; signum with 2 acute, flattened spines projecting inwards from

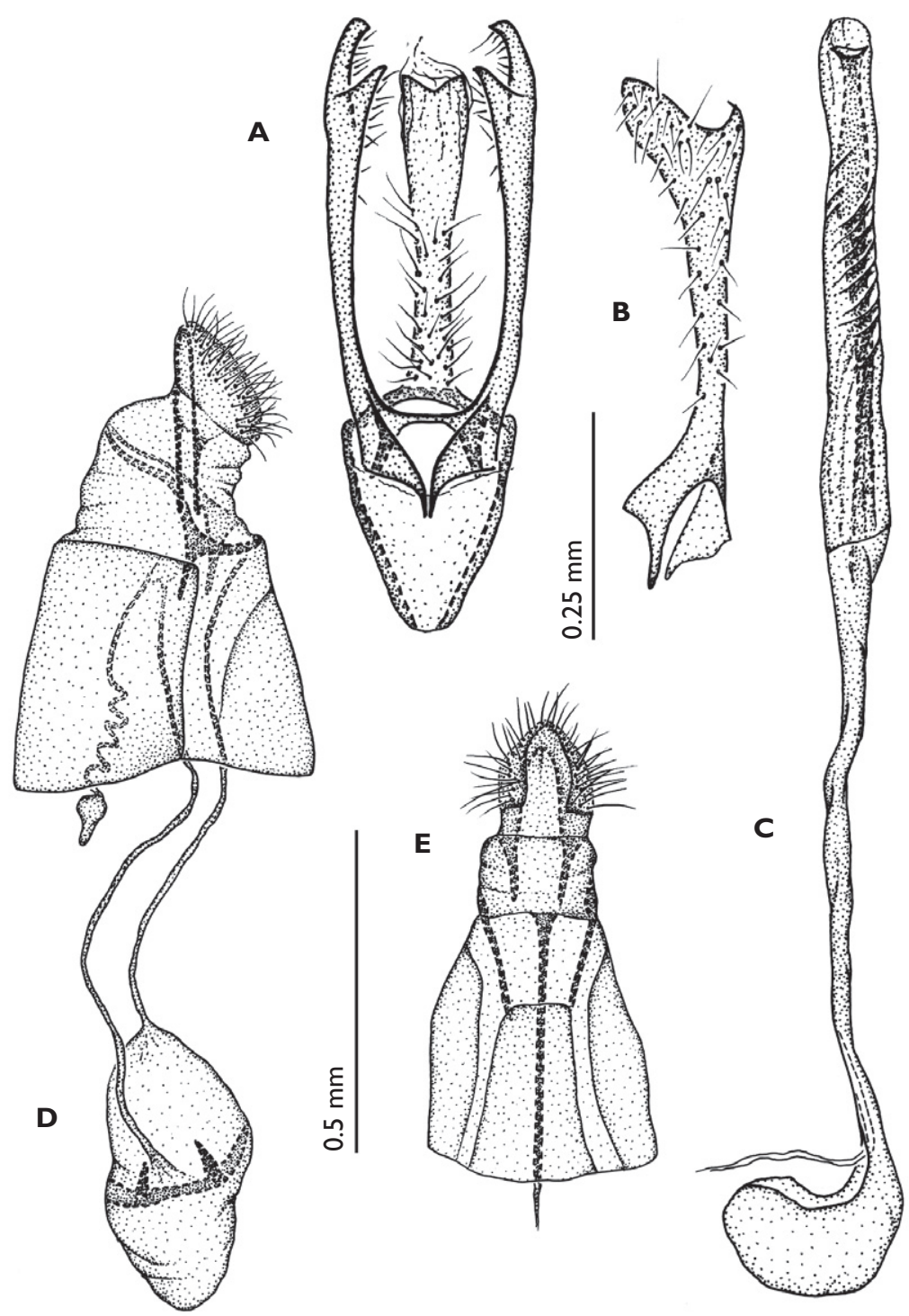

Figure 6. Phyllocnistis tropaeolicola sp. n., genitalia. A Male, ventral view B right valva, mesal view C aedeagus $\mathbf{D}$ female, lateral view $\mathbf{E}$ ventral view of terminal segments. (Scale bar $0.5 \mathrm{~mm}$ except for figure B, $0.25 \mathrm{~mm}$.) 

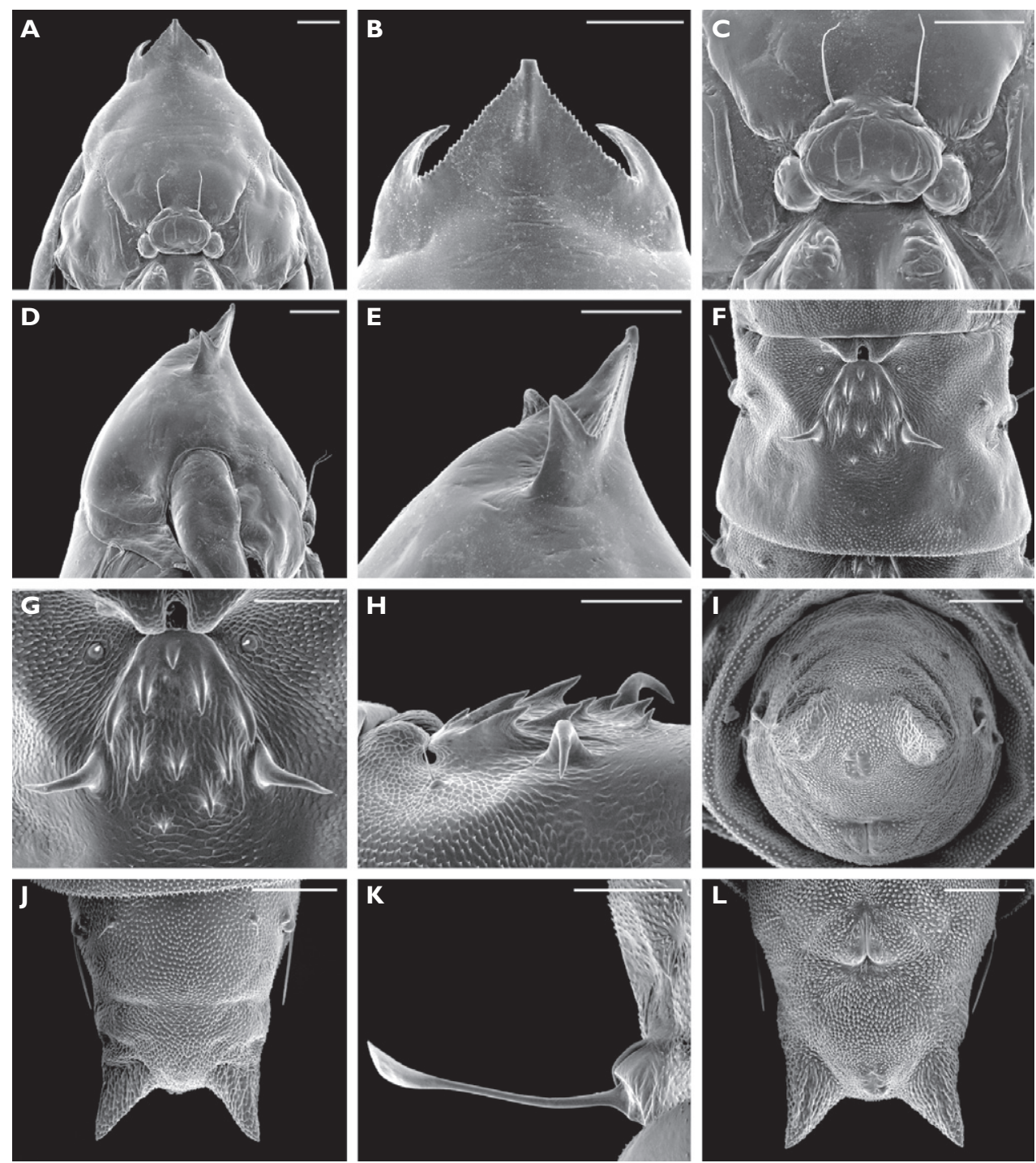

Figure 7. Phyllocnistis drimiphaga sp. n., pupa. A Ventral view of head B ventral view of cocoon-cutter $\mathbf{C}$ frons $\mathbf{D}$ lateral view of head $\mathbf{E}$ lateral view of cocoon-cutter $\mathbf{F}$ dorsal view of fifth abdominal tergum $\mathbf{G}$ spines on fifth abdominal tergum $\mathbf{H}$ lateral view of spines on fifth abdominal tergum $\mathbf{I}$ view of abdominal tip $\mathbf{J}$ dorsal view of A9-10 K lateral seta on seventh abdominal tergum $\mathbf{L}$ ventral view of A9-10. Scale bars $100 \mu \mathrm{m}$.

band; length of spines slightly more than width of signa; ductus seminalis extremely slender, elongate, $-2.4 \times$ length of corpus bursae and arising from near middle of corpus bursae. Genitalia slide USNM 33282, 33285, 33288.

Larva (Figs 12A, C-F). Young sap-feeding larva translucent yellow (Fig. 12A). Mature sap-feeding larva $-7.5 \mathrm{~mm}$ long, translucent yellow, head capsule translucent pale brown, prothoracic shield dark brown (Figs 12C-). Cocoon-spinning larva whitish yellow, head capsule pale gray brown; $-6.5 \mathrm{~mm}$ long (Fig. 12F). 

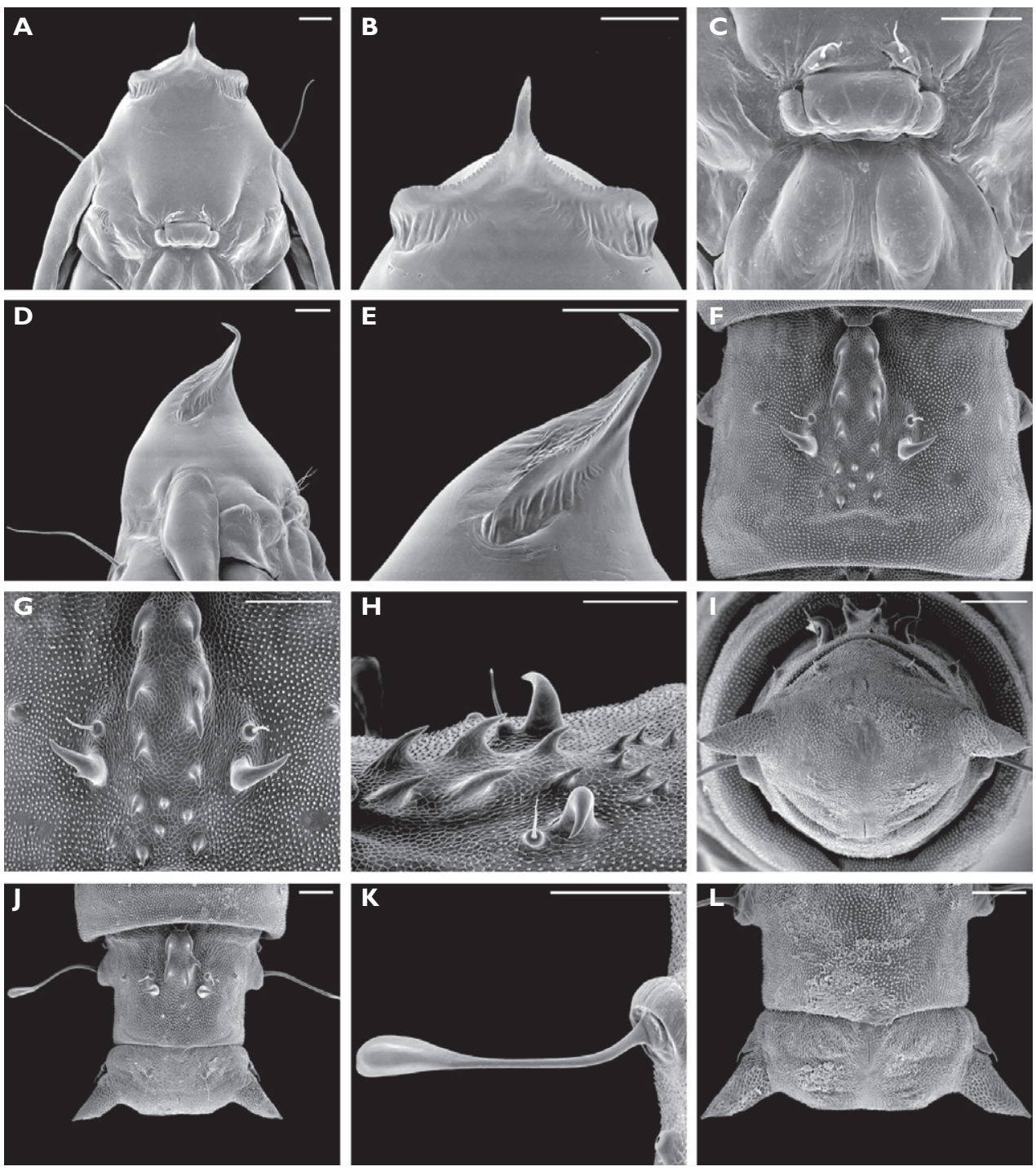

Figure 8. Phyllocnistis maxberryi sp. n., pupa. A Ventral view of head $\mathbf{B}$ ventral view of cocoon-cutter $\mathbf{C}$ frons $\mathbf{D}$ lateral view of head $\mathbf{E}$ lateral view of cocoon-cutter $\mathbf{F}$ dorsal of sixth abdominal tergum $\mathbf{G}$ spines on sixth abdominal tergum $\mathbf{H}$ lateral view of spines on seventh abdominal tergum $\mathbf{I}$ view of abdominal tip $\mathbf{J}$ dorsal view of A9-10 K lateral seta on sixth abdominal tergum $\mathbf{L}$ ventral view of A9-10. Scale bars $100 \mu \mathrm{m}$.

Pupa (Figs 10, 12H). Brown, length up to $-5 \mathrm{~mm}$; diameter $\sim 1.0 \mathrm{~mm}$. Vertex with a short, stout, process (cocoon-cutter) flanked by two, flattened, slightly longer processes (Figs 9A, B, D, E) and two pairs of short setae (Fig. 9C). Dorsum of A2-A7 with a pair of laterally curved, large spines in between which is a concentration of smaller spines, arranged in a triangular, V-shaped pattern (Figs 9F, G); each segment with a pair of long, lateral, sensory setae (Fig. 9L) that are shortest on A9-10 (Figs 9J, K). A10 with a pair of slightly divergent processes from caudal apex (Figs 9I, J). 

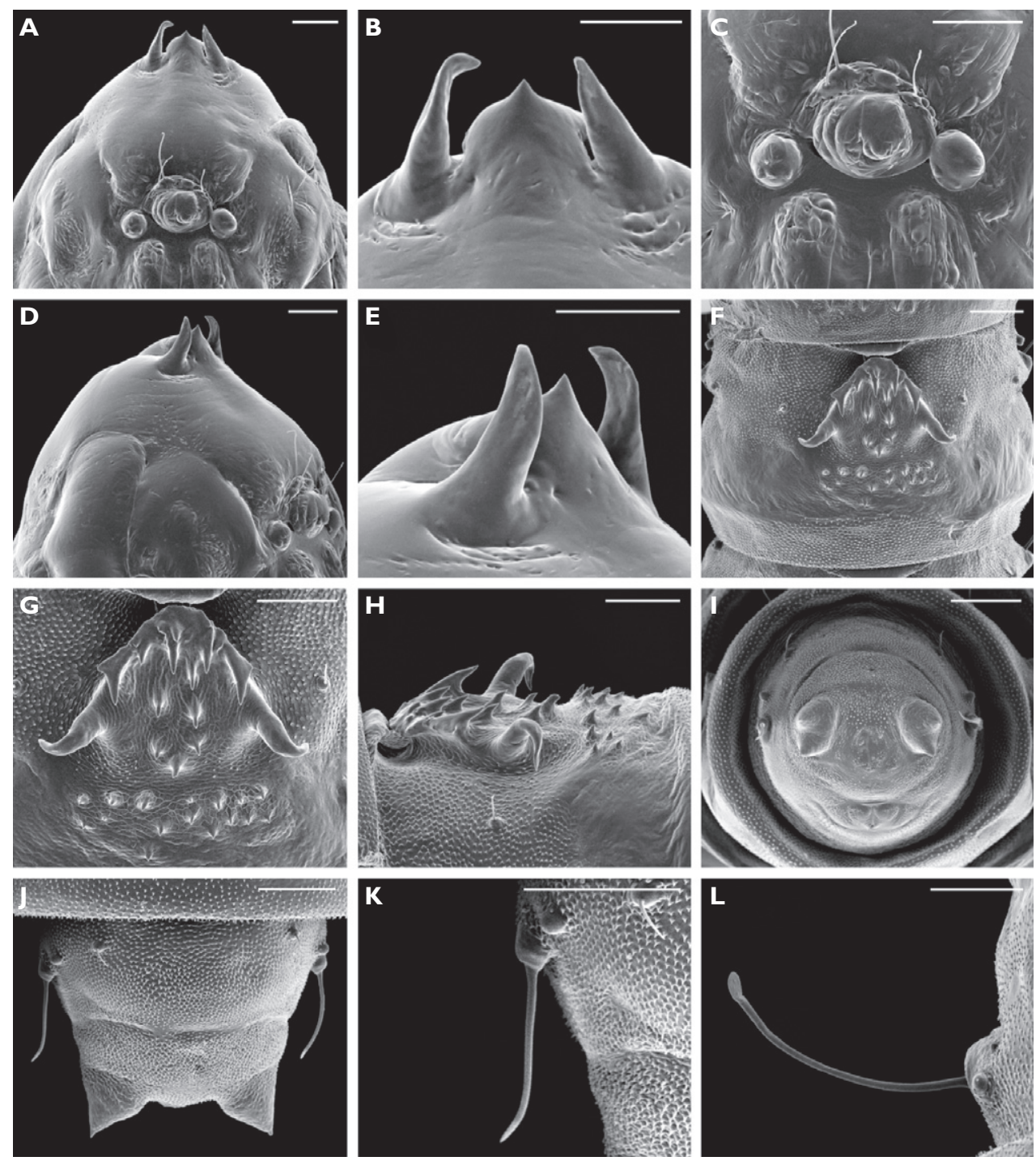

Figure 9. Phyllocnistis tropaeolicola sp. n., pupa. A Ventral view of head B ventral view of cocoon-cutter $\mathbf{C}$ frons $\mathbf{D}$ lateral view of head $\mathbf{E}$ lateral view of cocoon-cutter $\mathbf{F}$ dorsal view of fourth abdominal tergum $\mathbf{G}$ spines on fourth abdominal tergum $\mathbf{H}$ lateral view of spines on fourth abdominal tergum $\mathbf{I}$ view of abdominal tip J dorsal view of A9-10 K lateral seta on A9-10 L lateral seta on seventh abdominal tergum. Scale bars $100 \mu \mathrm{m}$.

Types. Holotype (Fig. 2C): $\widehat{O}$, Costa Rica: Prov. Cartago, Cerro de la Muerte, Villa Mills, 3100 m, 13 Mar 2003 (adult emergence), host Tropaeolum emarginatum, col./ rear Kenji Nishida, mine with pupal fold collected 6 Mar 2003 (USNM). Paratypes: Immatures: 1 prepupa, 1 pupa (USNM 34036), Villa Mills, Georgina, 9³3'30"N, 83²3'25.8"W, 3103 m, 12 Sep 2008, K. Nishida, host Tropaeolum emarginatum. Adults: same locality as holotype, $6 \hat{0}, 49$ : $\AA$ slide USNM 33281, $q$ slide USNM 

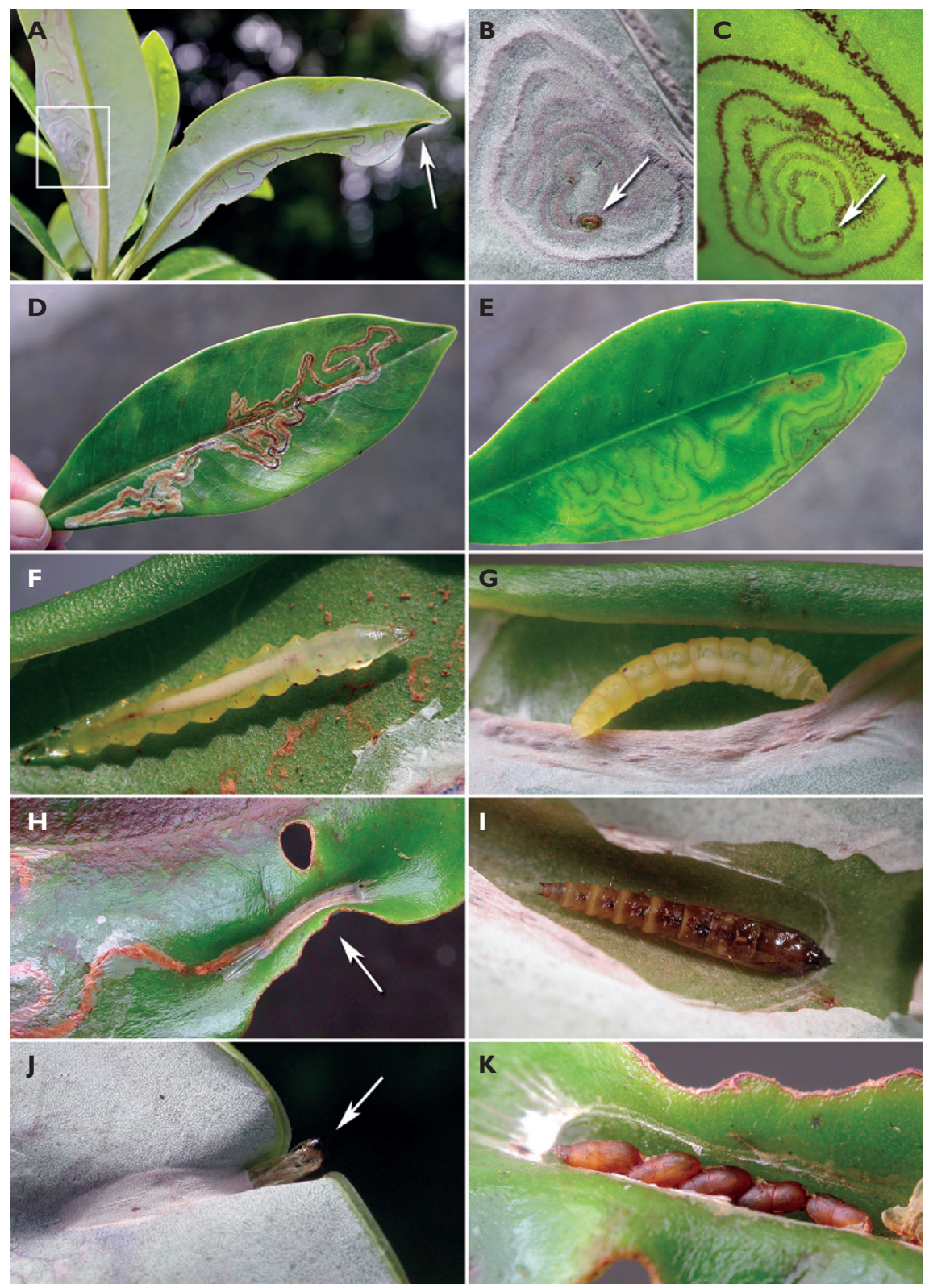

Figure 10. Life history of Phyllocnistis drimiphaga sp. n. A Leaf mines on abaxial side of leaf surface, white square enclosing early mine, arrow pointing to pupal cocoon fold B close-up view of early mine, arrow pointing to egg shell remains $\mathbf{C}$ same as figure B, but showing frass pattern (photo taken with sunlight projecting through the leaf from behind) $\mathbf{D}$ nearly mature old mine on adaxial side $\mathbf{E}$ nearly mature old mine on abaxial side (photo taken from adaxial side) $\mathbf{F}$ opened mine showing mature sapfeeding larva in situ $\mathbf{G}$ opened young pupal cocoon fold showing cocoon-spinning larva in situ $\mathbf{H}$ pupal cocoon fold on adaxial mine I opened pupal cocoon fold showing pupa in situ (dorsal view) $\mathbf{J}$ protruded and attached pupal shell (arrow) on pupal cocoon fold of an abaxial leaf mine $\mathbf{K}$ opened pupal cocoon fold on adaxial mine showing Ageniaspis cocoons in situ. 

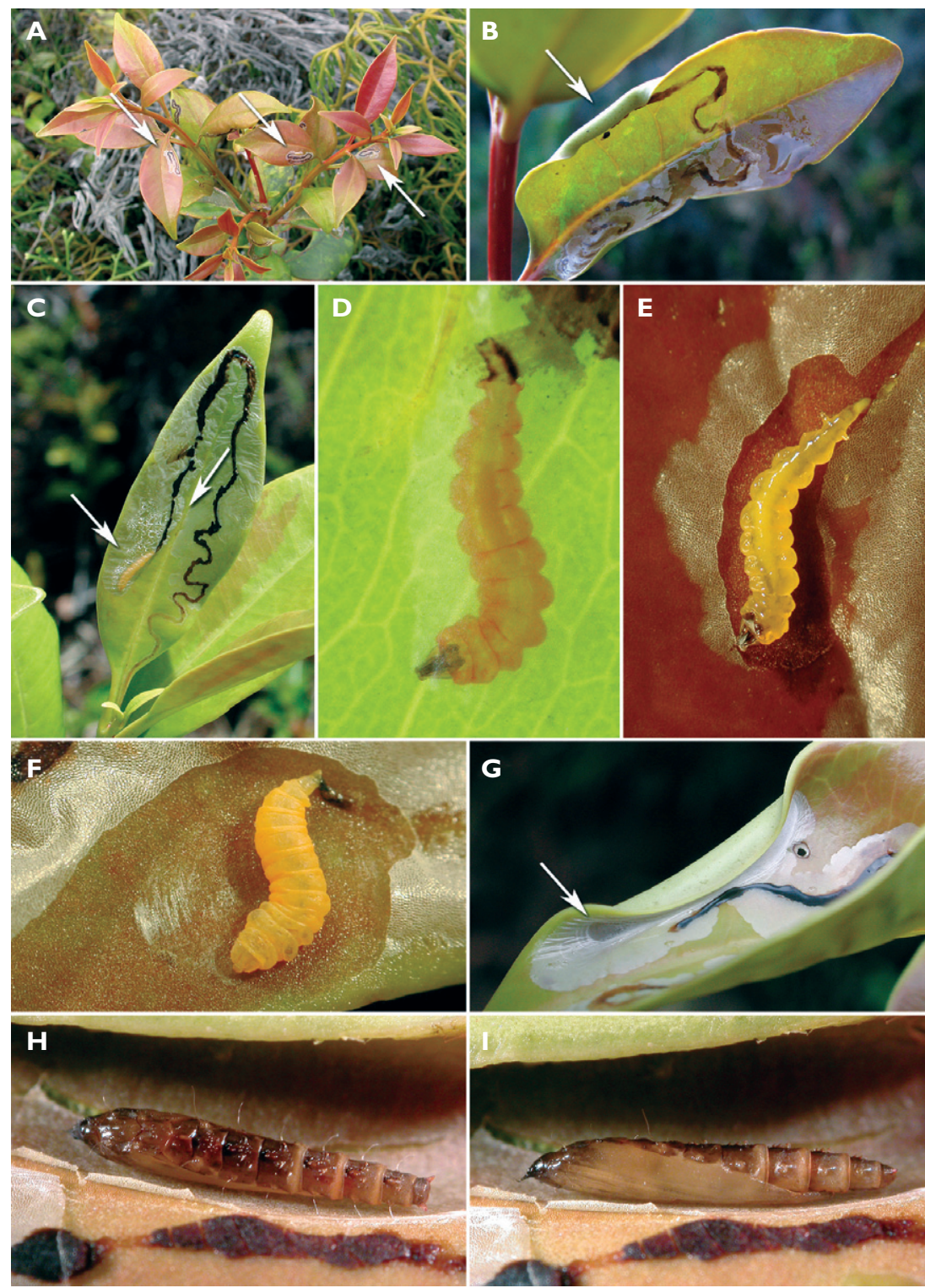

Figure II. Life history of Phyllocnistis maxberryi sp. n. A Leaf mines on young growing Gaiadendron shoot $\mathbf{B}$ mature mine with pupal cocoon fold (arrow) $\mathbf{C}$ nearly mature mine and mature sap-feeding larva (left arrow), and oviposition location (right arrow) D close-up view of mature sap-feeding larva $\mathbf{E}$ opened mine showing mature sap-feeding larva in situ $\mathbf{F}$ opened young pupal cocoon fold showing cocoonspinning larva in situ $\mathbf{G}$ pupal cocoon fold, arrow pointing at thinner pupal exit $\mathbf{H}$ opened pupal cocoon fold showing pupa in situ, dorsal view I pupa in situ, lateral view. 

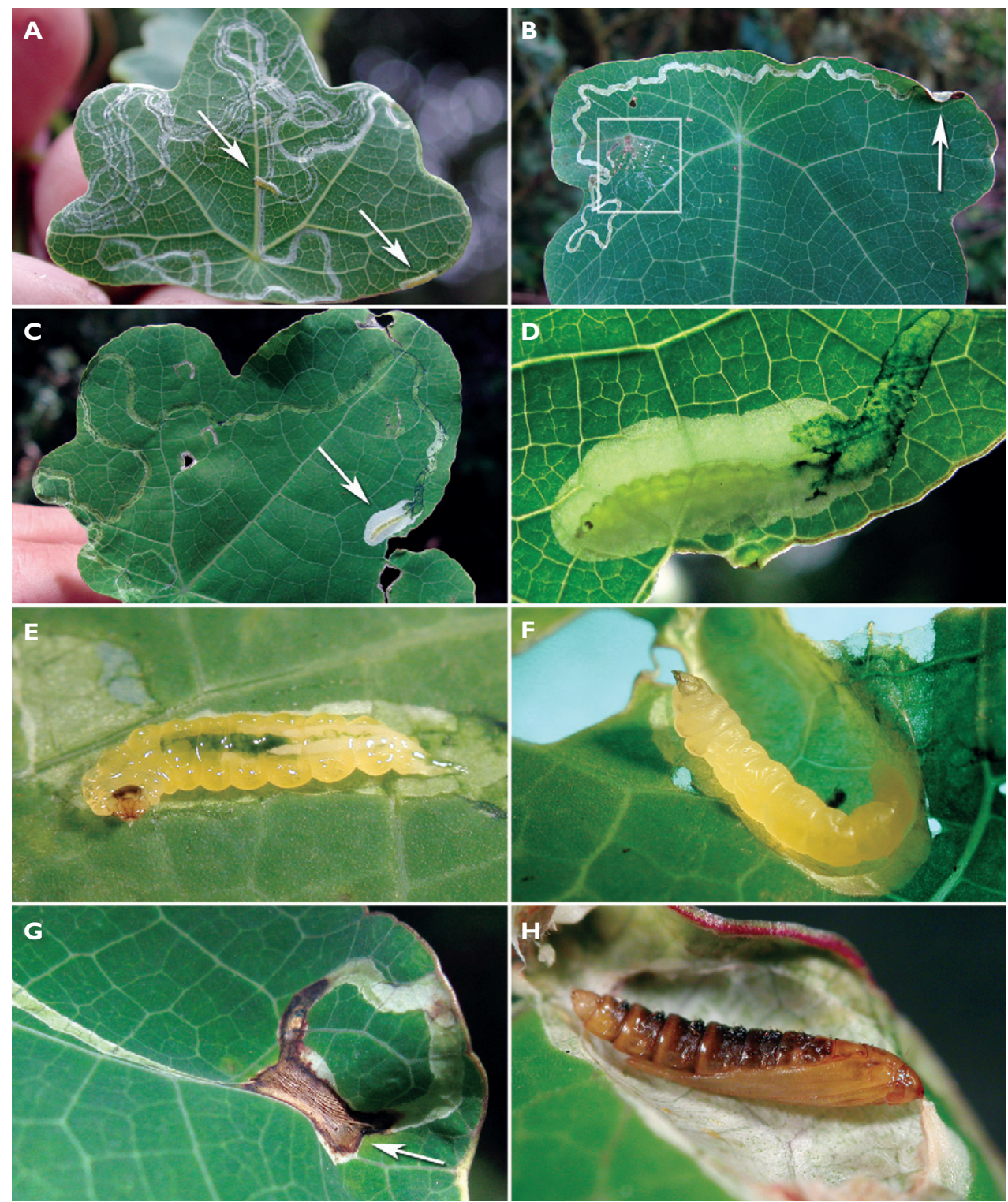

Figure 12. Life history of Phyllocnistis tropaeolicola sp. n. A Leaf mines on a young leaf, arrows pointing at young to middle instar larvae B mature leaf mine with pupal cocoon fold (arrow), white square enclosing early stage mine region $\mathbf{C}$ mature sap-feeding larva in pre-cocoon chamber $\mathbf{D}$ detailed view of figure $\mathbf{C} \mathbf{E}$ opened mine showing nearly mature sap-feeding larva in situ $\mathbf{F}$ opened young pupal cocoon fold showing cocoon-spinning instar in situ $\mathbf{G}$ pupal cocoon fold, arrow pointing to the slender exit $\mathbf{H}$ opened pupal cocoon fold showing pupa in situ, dorsolateral view. 
$33285 ; 2 \partial^{\lambda}, 29$ (USNM 33280, 33282) with adult emergence 11 Mar 2003; $1 \partial^{\lambda}$, with adult emergence 15 Mar 2003. 1 ㅇ adult paratype at INBio and UCR, the remaining paratypes at USNM.

Life history (Fig. 12). Mines of P. tropaeolicola were readily found on plants growing along the Pan-American Highway (Fig. 1H). Most mines occurred on full-grown new leaves (Figs 12B, C) but some were found on developing leaves (Fig. 12A). Thirteen had a single mine, two leaves had two, and one had three. All mines were found on the adaxial side, and the late sap-feeding instar fed on the mesophyll (Fig. 12E).

The mine characteristically begins as a narrow, irregular serpentine gallery (Fig. $12 \mathrm{~B}$ ) that widens as it extends along or near the leaf margin (Figs 12B, C). It is relatively narrow, pale green to white with a less conspicuous dark green median frass line. Pupal cocoon folds were $-5.5 \mathrm{~mm}$ long and were found near the leaf margin (Figs 12B, G). Adults emerged 5-9 days after pupal cocoon folds were collected.

We found mines of an unidentified fungus gnat (Diptera: Mycetophilidae) at same site on the same plant. The mines, which usually occur several on a single leaf, are irregularly shaped blotch mines with dark-green frass scattered randomly within. The fly larva causes curling, drying, necrosis, and yellowing of the leaves, and was more abundant than P. tropaeolicola mines. Several leaves were infested with both mycetophilid and P. tropaeolicola larvae.

Host. Tropaeolum emarginatum Turcz (Tropaeolaceae) (Fig. 1I). Tropaeolum, the only genus recognized in Tropaeolaceae, is Neotropical and contains approximately 90 species, many of which are found in Andean cloud forests (Gentry 1996). Four species occur in Costa Rica, and T. emarginatum is present on both the Atlantic and Pacific slopes between 700 and $3200 \mathrm{~m}$ (Alfaro-Vindas 2003; INBio 2009). Outside Costa Rica, T. emarginatum has been recorded from Chiapas, Mexico to Cotopaxi, Ecuador (Missouri Botanical Garden 2009). The tenuous, soft, and succulent vines of T. emarginatum are usually found in forest edges and disturbed areas, and the flowers are red to yellow orange (Alfaro-Vindas 2003; Gentry 1996). Most of the leaves are between 5 and $8 \mathrm{~cm}$ wide ( $\mathrm{KN}$, pers. obs.).

Distribution. Known only from the type locality, Cerro de la Muerte, Villa Mills, at $3100 \mathrm{~m}$ elevation in the Cordillera de Talamanca.

Etymology. The species name, tropaeolicola, is formed from its host plant genus name, Tropaeolum, and the Latin word cola, meaning "inhabitant".

\section{Acknowledgements}

We thank David L. Wagner, University of Connecticut, Storrs, who provided valuable comments on Phyllocnistis. Conrad C. Labandeira, Department of Paleobiology, Smithsonian Institution, contributed to the date of the oldest phyllocnistine fossil mine. We are indebted to Jurate De Prins, Royal Museum of Central Africa, Tervuren, Jae-Cheon Sohn, University of Maryland, and an anonymous reviewer for comments on the manuscript. Scott Whittaker, SEM Laboratory Manager, Laboratories of Ana- 
lytical Biology, Smithsonian Institution, Washington D.C. assisted with SEM photography. Miriam Erandi Reyna-Fabian, Universidad National Autonoma de México, assisted with the preparation of SEM figures. Vichai Malikul and Young Sohn, Department of Entomology, Smithsonian Institution, and Diana Marques prepared line drawings. Patricia Gentili-Poole assisted in preparing several plates and photographing the adults. Oscar Abarca Hotel-Restaurante La Georgina provided climate conditions of Villa Mills region. Luis Guillermo Chaverri, INBio, identified the mycetophilid larva and Christer Hansson, Department of Cell and Organism Biology, Lund University, identified the eulophid parasitoid wasp. Research at the Vara Blanca transect was supported by the ALAS IV project to AYK, KN and DRD (supported by National Science Foundation grant DEB-0072702 and co-principal investigator John Longino). We thank Javier Guevara, Sistema Nacional de Áreas de Conservación de Costa Rica (SINAC) for providing permits. Additional laboratory and field research was funded by three grants to AYK: the Exploration Fund Grant from the Explorer's Club New York, the Christiane and Christopher Tyson Fellowship from the Organization for Tropical Studies (OTS), and a Smithsonian Institution Fellowship provided by Mary Sangrey, Head of Academic Services, Smithsonian Institution.

\section{References}

Alfaro-Vindas E (2003) Plantas comunes del Parque Nacional Chirripó = Common plants of Chirripó National Park - Costa Rica. Instituto Nacional de Biodiversidad, Santo Domingo de Heredia, 268 pp.

Brenner RL, Ludvigson GA, Witzke BJ, Zawistoski AN, Kvale EP, Ravn RL, Joeckel RM (2000) Late Albian Kiowa-Skull Creek marine transgression, Lower Dakota Formation, eastern margin of Western Interior Seaway, USA. Journal of Sedimentary Research 70: 868-878.

Davis DR (1987) Gracillariidae. In: Stehr FW (Ed) Immature insects. Kendall/Hunt, Dubuque, 372-374.

Davis DR (1994) New leaf-mining moths from Chile, with remarks on the history and composition of Phyllocnistinae (Lepidoptera: Gracillariidae). Tropical Lepidoptera 5: $65-75$.

De Prins J, De Prins W (2009) Global Taxonomic Database of Gracillariidae (Lepidoptera). World Wide Web electronic publication (http://gc.bebif.be) [accessed 13 October 2009].

De Prins J, Kawahara AY (2009) On the taxonomic history of Phyllocnistis Zeller (Lepidoptera: Gracillariidae). Nota Lepidopterologica 32: 27-35.

De Prins W, De Prins J (2005) Gracillariidae (Lepidoptera). In: Landry B (Ed) World Catalogue of Insects, Vol. 6. Apollo Books, Stenstrup, 502 pp.

Doust AN, Drinnan AN (2004) Floral development and molecular phylogeny support the generic status of Tasmannia (Winteraceae). American Journal of Botany 91: 321-331.

Gentry AH (1996) A field guide to the families and genera of woody plants of northwest south America (Colombia, Ecuador, Peru) with supplementary notes on herbaceous taxa. University of Chicago Press, Chicago, $x+895$ pp. 
Grimaldi D, Engel MS (2005) Evolution of the Insects. Cambridge University Press, Cambridge, $772 \mathrm{pp}$.

Hartshorn GS (1983) Drimys winteri (Quiebra Muelas, Muelo, Chile Muelo, Drimys). In: Janzen

DH (Ed) Natural history of Costa Rica. University of Chicago Press, Chicago, xi +816 .

Heppner, J B (1993) Citrus leafminer, Phyllocnistis citrella Stainton (Lepidoptera: Gracillariidae: Phyllocnistinae). Entomology Circular No. 359, Fla. Dept. Agric. \& Consumer Services Division of Plant Industry, pp. 1-2.

Herrera W, Gómez LD (1993) Mapa de unidades bióticas de Costa Rica. Escala 1:685.000. US Fish \& Wildlife Service, San José.

INBio (2009) Instituto Nacional de Biodiversidad. Atta. Jerarquía Taxonómica. Available from http://www.inbio.ac.cr/bims/BIMS.html (accessed 19 April 2009).

Kappelle M (1996) Los bosques de roble (Quercus) de la Cordillera de Talamanca, Costa Rica: Biodiversidad, Ecología, Conservación y Desarrollo. Universidad de Amsterdam, Instituto Nacional de Biodiversidad (INBio), Amsterdam and Santo Domingo de Heredia, 336 pp. Kappelle M (2008) Biodiversidad de los bosques de roble (encino) de la América tropical = Biodiversity of the oak forests of tropical America. Instituto Nacional de Biodiversidad, Santo Domingo de Heredia, 336 pp.

Labandeira CC, Dilcher DL, Davis DR, Wagner DL (1994) Ninety-seven million years of angiosperm-insect association: paleobiological insights into the meaning of coevolution Proceedings of the National Academy of Sciences of the United States of America 91: $12278-12282$.

Missouri Botanical Garden (2009) Tropicos.org. Missouri Botanical Garden. Available from http://www.tropicos.org/ [accessed 19 April 2009].

Nishida K (2006) Encounter with Hyla angustilineata Taylor, 1952 (Anura: Hylidae) in a cloud forest of Costa Rica. Brenesia 66: 79-81. 